\title{
Concentrations of metals in gastric juice in health and peptic ulcer disease
}

\author{
J J Powell, S M Greenfield, R P H Thompson
}

\begin{abstract}
The concentrations of essential metal cations in gastric juice, collected at endoscopy from 17 normal patients and 11 with peptic ulcer disease, were determined by inductively coupled plasma emission spectrometry. Mean fasting levels in normal gastric juice were as follows: sodium $47.7 \mathrm{mM}$, potassium 14.6 $\mathrm{mM}$, calcium $0.8 \mathrm{mM}$, magnesium $0.36 \mathrm{mM}$, zinc $13 \mu \mathrm{M}$, and copper $1.2 \mu \mathrm{M}$ : these did not differ significantly in health or disease. Because samples were contaminated with iron, the concentration of this metal was only estimated (ca $3.5 \mu M$ in normal subjects), and this secretion could represent a significant proportion of the daily loss of endogenous iron. The pH of gastric juice predicted the concentrations of magnesium and calcium, but not copper or zinc, in the juice. It is concluded that previously reported values for trace metals in gastric juice have been incorrect and that the very low amounts secreted in the gastric juice will not interfere with the absorption of other trace metals from the diet. In contrast, the concentrations of macroelements in gastric juice may be sufficient to stimulate the absorption of trace metals from the gut.

(Gut 1992; 33: 1617-1620)
\end{abstract}

Essential metal ions are required in the gut not only for nutrition but also for the integrity of the mucosa; zinc, for instance, can facilitate the healing of gastric ulcers.' Numerous factors affect the uptake and absorption of metals, including their concentration in the gut and the presence of other metals. High dietary concentrations or iron, for example, reduce the percentage of iron absorbed from the bowel, ${ }^{2}$ and while zinc, copper, and iron reduce the absorption of each other, ${ }^{3}$ recent work suggests that sodium, calcium, and magnesium may promote the absorption of some trace metals. ${ }^{+}$Continued secretion of cations into gastrointestinal fluids may therefore be important in influencing the absorption of dietary trace metals.

The concentrations of trace metals have been recently studied in saliva and gut secretions, ${ }^{5-7}$ but not in gastric juice, which contains appreciable concentrations of electrolyte cations. Earlier values for concentrations of copper and iron in gastric juice may not be reliable, because great care is needed to avoid contamination during collection and analysis: zinc has not been investigated. We have therefore examined the concentrations of the essential micro (trace) elements copper, iron, and zinc, and of the macroelements calcium, magnesium, potassium, and sodium in fasting human gastric juice obtained at endoscopy from healthy subjects and patients with peptic ulcer disease, and also determined for which metals the $\mathrm{pH}$ predicts concentrations."

\section{Methods}

\section{ASSESSMENT OF CONTAMINATION}

Metal concentrations were first measured in the endoscopy cleaning fluids, namely the detergent (Teepol MB7, Teepol Products) and the disinfectant (2\% glutaraldehyde solution, Totacide 28, Coventry Chemicals Ltd). Analyses were performed as below for gastric juice, by inductively coupled plasma emission spectrometry (ICPES).

The contamination of samples collected from the gastroscope was then estimated. The fibreoptic Olympus gastroscope was cleaned as for endoscopy and the fluid was discarded. To simulate collection of gastric juice, five separate $(5 \mathrm{ml})$ samples of double deionised acidified water $(\mathrm{pH} \mathrm{2 \cdot 0)}$ were consecutively aspirated through the gastroscope into acid washed universal containers (Sterilin Ltd) using the vacuum trap. This was repeated in triplicate and samples were analysed for metal ions by ICPES.

\section{COLLECTION OF GASTRIC JUICE}

Based on the results of these contamination studies (Fig 1), before each endoscopy and the collection of gastric juice, residual cleaning fluid in the scope was first disposed of and then two $5 \mathrm{ml}$ ultrapure acidified water samples were similarly collected and discarded. Gastric juice was then collected from patients undergoing routine diagnostic gastroscopy who had fasted for at least eight hours. Patients were excluded if they had a systemic illness requiring treatment

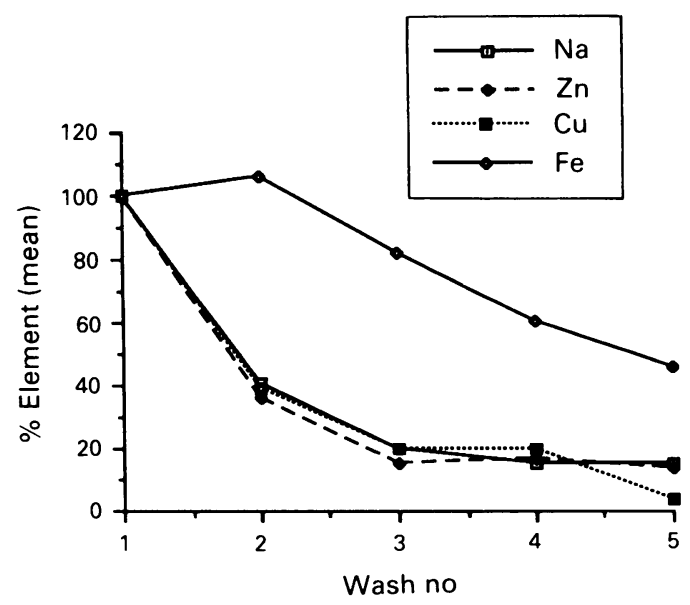

Figure 1: Decreases in contamination of acidified water by four metals after serial flushes through the endoscope, with concentration of the first wash taken as $100 \%$. 
or were currently being treated with antiulcer agents. To prevent aspirating saliva, suction was switched off during intubation until the gastroscope entered the stomach, and with minimal contact of the mucosa the fundal pool of gastric juice was aspirated, using the vacuum trap suction, into acid washed, metal free universal containers. An aliquot was taken for $\mathrm{pH}$ measurement and the remainder stored at $-20^{\circ} \mathrm{C}$ until analysis.

After gastroscopy, samples from patients with gastric erosions or oesophagitis were discarded, as was any sample in which mucus, blood, or bile pigment was seen, since blood or bile could cause erroneous results while the mucus binds metals. ${ }^{9-11}$ Only clear, colourless samples without obvious debris were therefore analysed and these were centrifuged to minimise contamination by particles that could block the spectrometer nebuliser. Fifty samples of gastric juice were collected and 22 rejected (oesophagitis $n=8$, gastric erosions $n=4$, and mucus/bile contamination $\mathrm{n}=10$ ).

\section{ANAL YSIS OF GASTRIC JUICE}

The thawed samples were spun at $1000 \mathrm{~g}$ for 10 minutes and $500 \mu \mathrm{l}$ aliquots were taken into a second acid washed plastic tube, diluted 1:9 with ultrapure $0.11 \mathrm{M}$ nitric acid, and analysed by ICPES (Philips PV 8050) at the following wavelengths: potassium $766.49 \mathrm{~nm}$, sodium $588.99 \mathrm{~nm}$, magnesium $383.83 \mathrm{~nm}$, copper $324.75 \mathrm{~nm}$, calcium $315.89 \mathrm{~nm}$, iron $259.94 \mathrm{~nm}$, and zinc $213.86 \mathrm{~nm}$. Dilution, spiking, and recovery experiments were performed for each element using a sample of pooled gastric juice, diluted as above. All elements gave a linear response except calcium, which had a reduced recovery at the higher spiked levels, but all levels in the diluted gastric juice were on the linear part of the graph. The activity of hydrogen ions of the samples was measured at $25^{\circ} \mathrm{C}$ using a standard $\mathrm{pH}$ electrode (Electronic Instruments Ltd) that was calibrated with two standards before each measurement. Proton concentrations for each sample were then calculated from the hydrogen ion activity and the combined sodium and potassium concentrations. ${ }^{12}$

\section{STATISTICS}

Logarithmic values of the data were taken to normalise their distribution and patient groups were compared by unpaired Student's $t$ test. Significance was set at $\mathrm{p}<0 \cdot 05$. Since there were no differences between the groups, data were combined for correlations between elements, except for iron which was excluded because of the unavoidable endoscopic contamination (see below). The proposal that concentrations of calcium and magnesium ${ }^{8}$ correlate with each other as well as with proton concentrations was examined. Correlations of copper to zinc, copper to protons, and zinc to protons were also investigated.

\section{Results}

Metal concentrations in glutaraldehyde and Teepol are shown in Table I.

Typical mean decreases in metal contamination from each successive collection of acidified water are shown in Figure 1. Curves were similar for all metals except iron, which had much higher contamination values even after five collections. For the other metals there was little further decrease in contamination after the third collection.

The demographic data of the patients whose gastric juice was analysed are shown in Table II. Six patients had gastric ulcers and five had duodenal ulcers. The mean metal concentrations in fasting gastric juice of patients is shown in Table III; there were no differences for any of the metals between the two groups of patients, nor were there differences between those with duodenal and gastric ulcers. Contamination was calculated from the concentrations in the aspirated water (Table IV); this would have only

TABLE I Metal concentrations of endoscopy cleaning fluids

\begin{tabular}{llc}
\hline Metal & Glutaraldehyde solution & Teepol MB7 \\
\hline $\mathrm{Na}(\mathrm{mM})$ & $34 \cdot 0$ & $>435$ \\
$\mathrm{~K}(\mathrm{mM})$ & $56 \cdot 0$ & $2 \cdot 0$ \\
$\mathrm{Ca}(\mathrm{mM})$ & 0.08 & 1.4 \\
$\mathrm{Mg}(\mathrm{mM})$ & 0.02 & 0.3 \\
$\mathrm{Fe}(\mu \mathrm{M})$ & $1 \cdot 10$ & $12 \cdot 4$ \\
$\mathrm{Zn}(\mu \mathrm{M})$ & $0 \cdot 15$ & $1 \cdot 1$ \\
$\mathrm{Cu}(\mu \mathrm{M})$ & 0.94 & $5 \cdot 2$ \\
\hline
\end{tabular}

TABLE II Demographic data of patients

\begin{tabular}{llc}
\hline & $\begin{array}{l}\text { Normal } \\
\text { group } \\
(n=17)\end{array}$ & $\begin{array}{l}\text { Peptic ulcer } \\
\text { disease group } \\
(n=11)\end{array}$ \\
\hline M:F & $10: 7$ & $7: 4$ \\
Mean (SEM) age (years) & $38 \cdot 0(3 \cdot 3)$ & $41 \cdot 8(3 \cdot 8)$ \\
Mean (SEM) pH of gastric juice & $2 \cdot 0(0 \cdot 17)$ & $1 \cdot 8(0 \cdot 14)$ \\
\hline
\end{tabular}

TABLE III Metal and proton concentrations in gastric juice (values mean $(S E M)$ )

\begin{tabular}{llc}
\hline & $\begin{array}{l}\text { Normal } \\
\text { group } \\
(n=17)\end{array}$ & $\begin{array}{l}\text { Peptic ulcer } \\
\text { disease group } \\
(n=11)\end{array}$ \\
\hline $\mathrm{Na}(\mathrm{mM})$ & $47 \cdot 70(5 \cdot 4)$ & $48 \cdot 70(5 \cdot 58)$ \\
$\mathrm{K}(\mathrm{mM})$ & $14 \cdot 60(0 \cdot 92)$ & $13 \cdot 00(2 \cdot 20)$ \\
$\mathrm{Ca}(\mathrm{mM})$ & $0 \cdot 80(0 \cdot 08)$ & $0.95(0 \cdot 12)$ \\
$\mathrm{Mg}(\mathrm{mM})$ & $0 \cdot 36(0 \cdot 03)$ & $0 \cdot 28(0 \cdot 03)$ \\
$\mathrm{Fe}(\mu \mathrm{M})$ & $5 \cdot 20(0 \cdot 60)^{\star}$ & $3 \cdot 78(0 \cdot 66)^{\star}$ \\
$\mathrm{Zn}(\mu \mathrm{M})$ & $13.00(0 \cdot 60)$ & $12 \cdot 10(2 \cdot 50)$ \\
$\mathrm{Cu}(\mu \mathrm{M})$ & $1 \cdot 22(0.26)$ & $1 \cdot 28(0 \cdot 25)$ \\
$\mathrm{H}^{+}(\mathrm{mM})$ & $27 \cdot 00(5 \cdot 58)$ & $30 \cdot 30(7 \cdot 54)$ \\
\hline
\end{tabular}

There were no differences between the two patient groups for any metal analysed. ${ }^{\star}$ Samples contaminated (see text).

TABLE IV Calculated contamination of aspirate by metals from endoscope (values mean (SEM))

\begin{tabular}{llllllll}
\hline & $N a(m M)$ & $K(m M)$ & $C a(m M)$ & $M g(m M)$ & $F e(\mu M)$ & $Z n(\mu M)$ & $C u(\mu M)$ \\
\hline $\begin{array}{l}\text { Concentration in gastric } \\
\text { juice }(\mathrm{n}=28)\end{array}$ & $48.1(3.86)$ & $13.98(1.02)$ & $0.89(0.069)$ & $0.32(0.02)$ & $4.64(0.46)$ & $12.65(1.89)$ & $1.25(0.18)$ \\
$\begin{array}{l}\text { Concentration in third } \\
\text { water sample }\end{array}$ & $0.048(0.012)$ & $0.022(0.007)$ & $0.024(0.009)$ & $0.0008(0.0008)$ & $1.68(0.83)$ & $0.41(0.10)$ & $0.092(0.009)$ \\
$\begin{array}{l}\text { Contamination of gastric } \\
\text { juice from endoscope }\end{array}$ & $0.10(0.02)$ & $0.16(0.05)$ & $2 \cdot 70(1.01)$ & $0.25(0.25)$ & $36.2(17.9)$ & $3.24(0.79)$ & $7.36(0.72)$ \\
\hline
\end{tabular}




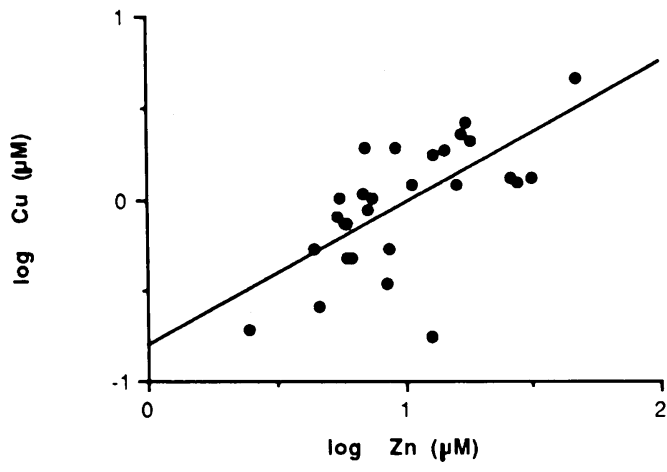

Figure 2: Correlation between zinc and copper concentrations in fasting gastric juice $(r=0.66, p<0.0001)$.

minimally increased $(0 \cdot 2-7 \cdot 4 \%)$ these values, except for iron, for which the concentrations could therefore only be estimated $(3.5 \mu \mathrm{M}$ in normal gastric juice), assuming that about one third of the recorded values (that is ca $1.7 \mu \mathrm{M}$; Table III) was a result of unavoidable contamination of samples.

Copper and zinc concentrations in gastric juice correlated positively $(\mathrm{r}=0.66, \mathrm{p}<0.0001)$ (Fig 2 ), but neither correlated with proton concentrations. In contrast, calcium and magnesium concentrations correlated positively $(r=0 \cdot 49$, $\mathrm{p}<0.01$ ), and each also correlated positively with pH (Ca: $\mathrm{pH}, \mathrm{r}=0.61, \mathrm{p}<0.001 ; \mathrm{Mg}: \mathrm{pH}$, $\mathrm{r}=0.56, \mathrm{p}<0.002$ ) (Fig 3 and 4 , respectively).

\section{Discussion}

It is difficult to define the absolute composition of fasting gastric juice since it is unavoidably contaminated by saliva, and often bile and pancreatic juice, and because mucus may bind metals strongly. ${ }^{9-11}$ We reduced these variables by sampling from a pool of gastric juice with little mucosal contact and discarding any samples that were obviously contaminated, and the range of resulting values was therefore small. Interference is minimal for ICPES, ${ }^{13}$ so that sample pretreatment and matrix modification are often not needed, avoiding further contamination during analysis. Contamination and poor analytical techniques presumably explain why previous values ${ }^{1+15}$ for trace metals in gastric juice were so high. In addition, by washing the endoscope twice before gastroscopy we avoided contamination from the endoscopic cleaning fluids, which contained high concentrations of most metals measured.

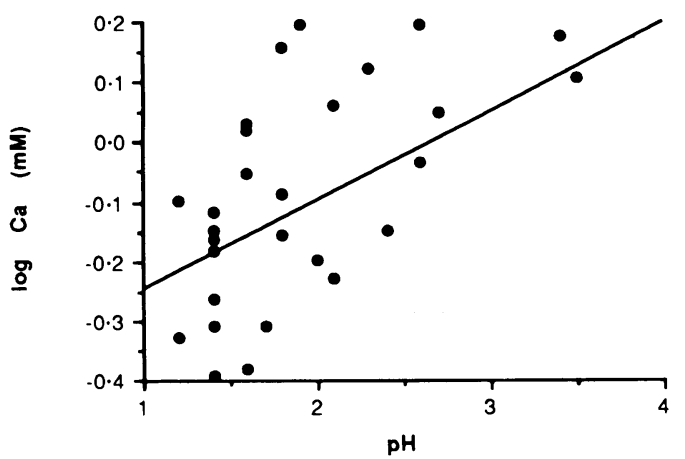

Figure 3: Correlation between calcium concentrations and $\mathrm{pH}$ in fasting gastric juice $(r=0.61, p<0.001)$.

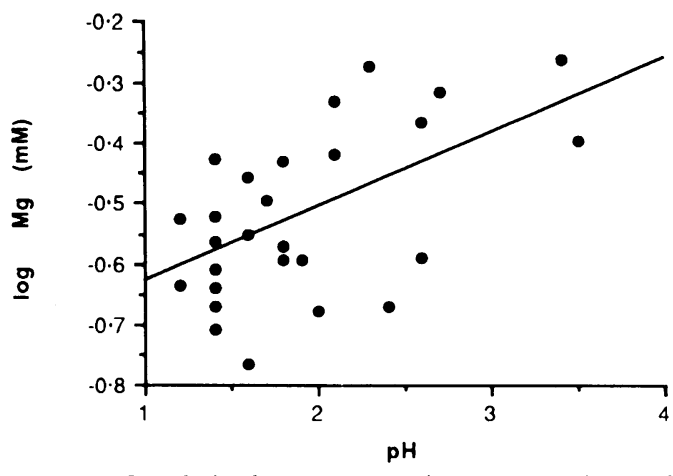

Figure 4: Correlation between magnesium concentrations and $\mathrm{pH}$ in fasting gastric juice $(r=0.56, p<0.002)$

Moore et al ${ }^{12}$ advise measuring the $\mathrm{pH}$ with correction for electrolyte levels to convert the hydrogen ion activity to concentration. Although this also requires the measurement of sodium and potassium, it is more accurate than standard titrimetric procedures, which are associated with non-linear errors. ${ }^{16}$

Iron concentrations $(3.5 \mu \mathrm{M})$ could only be estimated in gastric juice because of unavoidable contamination, but these were about 15-fold lower than previously reported values. ${ }^{15}$ Nevertheless, the data suggest that if levels were more accurate they would have been lower in the peptic ulcer group. Most metals in gastric juice, with the exception of parietal cell derived potassium, ${ }^{17}$ are of extracellular origin and diffuse into the gastric lumen, ${ }^{18}$ so the presence of any iron in fasting gastric juice is surprising since plasma iron is so tightly bound to transferrin. Weaker iron binding ligands within gastric juice such as citrate, ${ }^{19}$ or even the iron colloid binding glycoprotein 'gastroferrin'," may facilitate transfer of some iron into the stomach. Since ferric iron is poorly absorbed from the small intestine, that secreted into gastric juice (ca $0.2 \mathrm{mg} / \mathrm{l}$ ) will contribute appreciably to the daily loss of about $1 \mathrm{mg}$ of endogenous iron. ${ }^{21}$

The previous report ${ }^{14}$ of copper concentrations in gastric juice represents a fivefold overestimate: we found low concentrations only (mean $=1 \cdot 2 \mu \mathrm{M})$ and this is probably because most plasma copper (ca $80-90 \%$ ) is tightly bound to the plasma protein caeruloplasmin. ${ }^{21} \mathrm{Zinc}$ (13 $\mu M)$ in gastric juice has not been measured previously, but most zinc is only weakly bound to albumin ${ }^{21}$ in plasma and this probably explains why the zinc concentrations in gastric juice are higher relative to copper.

The absorption of trace metals from $\mathrm{mg}$ or $\mu \mathrm{g}$ oral doses is often used as a proxy for the physiological situation since only low levels of these elements are usually found in the diet. Although excess zinc may interfere with the absorption of iron ${ }^{2}$ and vice versa, ${ }^{21}$ it is unlikely that the low $\mu \mathrm{g}$ levels of trace metals that we have shown in gastric juice affect the absorption of exogenous trace metals. In contrast, the electrolyte cations are at relatively high concentrations in gastric juice and these may help to stimulate the absorption of trace metals in the intestine from the diet.

The concentrations of magnesium and calcium in gastric juice correlated with those of 
protons, in agreement with previous work. ${ }^{8}$ However, the concentrations of zinc and copper, although they correlated with each other, did not correlate with the levels of protons. Kinetic reasons are unlikely to explain this difference, since unchelated zinc and copper have rates of ligand exchange similar to those of magnesium and calcium, such as water exchange rate constants. ${ }^{22}$ Differential strengths of binding to mucus may explain this, 910 particularly since zinc and copper have greater affinity for most polyanionic metal binding substrates than magnesium and calcium. ${ }^{23}$ Thus, concentrations of zinc and copper may not correlate with concentrations of protons because the $\mathrm{pH}$ could have two opposing effects - it could facilitate the transfer of zinc and copper into gastric juice at a high $\mathrm{pH}$ but then only release them from mucus at low $\mathrm{pH}$.

Finally, none of the elemental concentrations in healthy subjects was different from those in the group with peptic ulcer disease (with the possible exception of iron), so the effect of zinc supplementation, which facilitates the healing of gastric ulcers, ' may not be due to the correction of cellular depletion, but rather a luminal or pharmacological effect.

In conclusion, we report mean fasting levels of copper $(1 \cdot 2 \mu \mathrm{M})$, and zinc $(13 \mu \mathrm{M})$ in the gastric juice of man. These two metals are probably plasma derived, and their concentrations are independent of the $\mathrm{pH}$ in gastric juice. In contrast, we confirm that $\mathrm{pH}$ predicts the concentrations of calcium and magnesium in gastric juice. Gastric juice may be a significant source for the daily loss of iron since it is present in gastric juice at about $3.5 \mu \mathrm{M}$, but correlation with gastric acidity or comparison between normal and ulcer patients could not be undertaken because of contamination. The concentration of other essential cationic metals in gastric juice did not differ between healthy subjects and those with peptic ulcer disease. The continued secretion into gastric juice of the cationic electrolyte elements may be beneficial for the intestinal absorption of dietary trace metals, but the secretion of trace elements into gastric juice is unlikely to interfere with the absorption of other trace metals from the diet.
We thank Mr N Taub for statistical advice and are grateful to the Special Trustees of St Thomas's Hospital for their continuing support.

1 Escolar G, Bulbena O. Zinc compounds, a new treatment in peptic ulcer. Drugs Exptl Clin Res 1989; XV: 83-9.

2 Reptic ulcer. Drugs Exptl Clin Res 1989; XV: 83-9. Rossander-Hulten L, Brune M, Sandstrom B, Lonnerdal B,
Hallberg L. Competitive inhibition of iron absorption by manganese and zinc in humans. Am $\mathcal{F}$ Clin Nutr 1991; 54: $152-6$.

3 Flanagan PR. Trace metal interactions involving the intestinal absorption mechanisms of iron and zinc. In: Dintzis FR, Laszlo JA, eds. Advances in experimental medicine and biology. Vol 249: 35-44: mineral absorption in the monobastric GI tract. New York: Plenum, 1989.

4 Adekalu JB, Heaton FW. Stimulation of trace element absorption by major metals in vitro. Proceedings of the Nutrition Society 1992; 51: 61:A.

5 Bales CW, Freeland-Graves JH, Askey S, Behmardi F, Pobocik RS, Fickel JJ, et al. Zinc, magnesium, copper, and protein concentrations in human saliva; age and sex-related differences. Am F Clin Nutr 1990; 51: 462-9.

6 Greger JL, Sickles VS. Saliva zinc levels: potential indicators of zinc status. Am $\mathcal{F}$ Clin Nutr 1979; 32: $1859-66$.

7 Ishihara N, Matsushiro T. Biliary and urinary excretion of metals in humans. Arch Environ Health 1986; 41: 324-30.

8 Hunt JN, Wain B. Electrolytes of mammalian gastric juice. In: Code CF, Werner H, eds. hand book of physiology. Section 6. Alimentary canal. Vol II. Secretion. Baltimore: Waverly, 1967: 781-804.

9 Crowther RS, Marriott C. Counter-ion binding to mucus glycoproteins. F Pharm Pharmacol 1984; 36: $21-6$.

10 Conrad ME, Umbreit JN, Moore EG. A role for mucin in the absorption of inorganic iron and other metal cations. Gastro-
and enterology 1991; 100: 129-36.

11 Coleman JR, Young LB. Metal binding by intestinal mucus. Scan Electron Microsc 1979; II: 801-6.

12 Moore EW. Determination of $\mathrm{pH}$ by the glass electrode; $\mathrm{pH}$ meter calibration for gastric analysis. Gastroenterology 1968; 54: 501-7.

13 Harvis I, Jarvis K. Plasma spectometry in the earth sciences. Chem Geol 1992; 95: 1-33.

14 Gollan JL, Davis PS, Deller DJ. Copper content of human alimentary secretions. Clin Biochem 1971; 4: 42-4.

15 Kimura I, Yamana M, Onoshi T, Nishizaki Y. The iron content of gastric juice: in relation to the cause of idiopathic
hypochromic anemia. Acta Haematol fpn 1968; 31: 199-203.

16 Mypochromic anemia. Acta Haematol fpn 1968; 31: 199-203. moore EW, Scarlata RW. The determination of gastric acidity
by the glass electrode. Gastroenterology 1965; 49: 178-88.

17 Malinowska DH, Sachs G. Cellular mechanisms of acid secretion. Clin Gastroenterol 1984; 13: 309-26.

18 Makhlouf GM, McManus JPA, Card WI. A quantitative statement of the two-component hypothesis of gastric secretion. Gastroenterology 1966; 51: 149-71.

19 Piper DW, Fenton BH, Goodman LR. Lactic, pyruvic, citric, and uric acid and urea content of human gastric juice. Gastroenterology 1967; 53: 42-8.

20 Rudzki Z, Baker RJ, Deller DJ. The iron-binding glycoprotein of human gastric juice. Digestion 1973; 8: 53-67.

21 Simmer K, Thompson RPH. Trace elements. In: Cohen RD, et al, eds. The metabolic and molecular basis of acquired disease. London: Bailière Tindall, 1990: 670-83.

22 Margenum DW, Cayley GR, Weatherburn DC, Pagenkopf $\mathrm{BK}$. Kinetics and mechanisms of complex formation and ligand exchange. In: Martell AE, ed. Coordination chemistry. Vol 2. ACS Monograph 174. Washington: American Chemical Society, 1978: 1-220.

23 Scott JE. Ion binding: patterns of 'affinity' depending on types of acid groups. In: Chantler E, Ratcliffe NA, eds. Symposia of the Society for Experimental Biology. No XLIII. Mucus and related topics. Cambridge: Society for Experimental Biology, 1989: 111-5. 